\title{
MITIGATION OF THE NEGATIVE EFFECTS OF RECYCLED AGGREGATE WATER ABSORPTION IN CONCRETE TECHNOLOGY
}

\author{
MATTHIAS ECKERT, MIGUEL OLIVEIRA \\ Civil Engineering Department, University of Algarve, Portugal
}

\begin{abstract}
The widespread use of natural aggregates in construction activities, together with the global population increase, gave rise to a depletion of this natural resource and to a progressive increase of its transport distances. On the other hand, the construction and demolition wastes (C\&DW) resulting from the construction activities are often deposited in landfills and city outskirts, causing environmental and social problems, such as erosion, deforestation, water contamination and human conflicts. The reuse of C\&DW in concrete preparation would be a good solution for both problems. Recycled aggregates show however high water absorption due to porosity. At saturation water flows from the inside to the engaging cement paste matrix and at dryness the opposite process occurs. This water flow breaks the aggregate-cement paste bonds and increases the $\mathrm{W} / \mathrm{C}$ ratio in the interfacial transition zone, and degrades the fresh and hardened concrete properties.

In this work a staged mixing method based on the aggregate water absorption over time was developed. A staged mixing procedure was optimized to regulate the water flow and manufacture concrete using recycled aggregates showing levels of workability, strength and shrinkage equivalent to those of conventional concrete. The physical, mechanical and geometrical properties of the aggregates were related to the properties of concrete in its fresh and hardened state. Three types of commercial recycled aggregates were evaluated. Two types of natural aggregates were also studied for comparison purposes.
\end{abstract}

\section{Keywords}

Recycled Aggregate, Concrete, Interfacial Transition Zone, Water Absorption, Compressive Strength, Shrinkage. 


\section{Biographical notes}

Matthias Bastian Eckert has a Master in Civil Engineering, specialization in Construction. He is currently a scholar and is doing research at the University of Algarve under the topic "Control of early age cracking in concrete and mortar, recycled aggregate concrete, self-compacting concrete".

Miguel José Oliveira is a Professor of the Director of the Civil Engineer Department of the University of Algarve, Portugal. He teaches courses in concrete technology, construction materials and quality and sustainability in construction. He is running the Laboratory of Construction Materials and has a small research group in the field. 


\section{INTRODUCTION}

Construction activity is a high consuming sector, accounting for the depletion of more than $40 \%$ of the energy and more than $50 \%$ of natural resources [1]. The current consumption of natural aggregates per year and per person is 3-5 tons [2]. The global use of natural aggregate will reach 26-44 Giga Tons per year in 2030 [2]. Construction is also responsible for the production of $50 \%$ of the global waste [1]. Recycling of C\&DW has been pointed by several governments as a solution to face these problems. The recycling of C\&DW is however a complex challenge due to the high heterogeneity associated to these materials. C\&DW and recycled aggregates (RA) prepared thereof generally show lower quality properties than natural aggregates (NA). Studies to define the conditions for their advantageous incorporation in concrete are therefore required [3]. Several works reported that the major problem of $R A$ is their high water absorption due to the high porosity of these materials [4, 5, 6, 7]. If the origin of aggregates is crushed concrete, the amount of water absorption depends on the porosity of the mortar attached to the natural stone [4]. The water absorption capacity ranges from 5 to $15 \%$, depending if the old mortar comes from low or high strength concrete, respectively [8] . RA obtained from ceramic D\&CW can absorb more than $30 \%$ of water [9].

A major challenge of the concrete technology is the preparation of concrete showing high performance in both, fresh and hardened states. It is well known that improving the workability reduces the properties of hardened concrete and vice-versa. The high water absorption of the RA makes this optimization even more difficult. Water addition to the mixes results in a higher W/C ratio, increasing the average distance between the binder particles, leading to high microstructural porosity of the concrete. Moreover, when the aggregates are pre-saturated with water, a water flow takes place from its inside to the involving cement paste matrix. This flow breaks the bonds [4] and leads to a higher W/C ratio on the interfacial transition zone (ITZ), which weakens the strength. It has been reported that the optimum water pre-saturation of RA should be about $80 \%$ [10].

This work reports an evaluation of the performance of different concrete mixtures prepared using distinct RA. All aggregates, including the control NA, were pre-saturated with water to its optimum moisture state, before cement addition. Tests of water absorption over time allowed the calculation of the extra water and absorption time required to reach the optimum moisture state. Based on the obtained results, a staged mixing approach [4] was followed and optimized to obtain the moisture state of the aggregates before addition of the binder to the mixture. After mixing, a slump test over time proved that there was no significant ITZ water flow and consequently no negative effects on the concrete microstructure. Several other aggregate properties were tested and related to the concrete performance in its fresh and hardened state

\section{STATE-OF-THE-ART}

The fresh state properties of recycled aggregate concrete (RAC) depends on the way how water absorption is compensated. When extra water is added to the mixture, the workability of RAC is better than that of ordinary concrete $(\mathrm{OC})$ at early stages. However, the fast water absorption of RA quickly reduces the workability [6]. If no extra water or superplasticizer is added, the workability of RAC is much lower than that of OC for the same W/C ratio [11]. Even if presaturating the RA is followed, the workability of RAC can be lower, due to the major shape index of this kind of aggregates. RAC usually shows a lower young's modulus $[12,13]$ and a higher poisons coefficient [14] in comparison with OC $[12,13]$. The young's modulus values can reduce $40-50 \%$ and the poisons coefficient can increase $0.02-0.03$, in comparison to that of. These properties have been related to a lower stiffness of this type of the RA. It is known that the percentage and stiffness of the aggregates are the main factors determining the stiffness of the concrete. The compressive strength of RAC is generally lower than that of OC and the reduction depends on the type and content of recycled aggregate $[5,14]$. It is reported that the decrease of compressive-strengths is proportional to the content of ceramic particles [15] but it also depends on the old mortar, attached to the natural stones, and the increase of the ITZ volume. The lower compressive strength is usually linked to the high water absorption process explained above [14]. 
Most papers reporting studies of RAC indicate that the tensile strength is higher or equal than that of OC. This has been associated with a smoother surface connected to the attached mortar which enables the formation of stronger bond strengths [16]. An alternative explanation is giving by the stiffness. The lower stiffness of the RA confers a smaller degree of internal restraint that attenuates the residual tensile stresses and microcracking perpendicular to the aggregates. Results of shrinkage tests are scarce. While some refer that the shrinkage of RAC can be lower than that of $O C$ when the aggregates are pre-saturated due to internal curing, others report high shrinkage strains of RAC caused by higher water absorption [17] and percentage of fines that this type of aggregate have [18]. Some papers even report different trends over time by comparing the shrinkage strain of $O C$ and RAC, caused by a competition of the mentioned factors along the curing process. No works about early age cracking are reported and very few results of creep [17] can be found in the literature. However these properties depend on the young's modulus and shrinkage of the concrete. All parameters used to evaluate the durability of concrete are worse in RAC than of OC, due to the porosity of these aggregates. RAC is more permeable [19], has a higher water absorption [20] [21], a lower electric resistivity [22] and a greater (1,3-2,5 times) carbonation depth [23] than OC.

\section{CHARACTERIZATION OF AGGREGATES}

The aggregates were provided by the recycling plant "Multi-Triagem" which collects and manages the C\&DW from the SW of the Algarve, Portugal. The primary reduction of the rubble was made with a shear. Then a primary and secondary crushing was performed using a portable Impact Crusher, fitted with two hammers and a magnetic separator. Finally the aggregates were sieved to obtain the desired fraction. In this work 5 types of coarse aggregates, labeled RA1, RA2, RA3, NA1 and NA2 and two types of fine aggregates, labeled RS and CS, were analyzed. The NA and $\mathrm{CS}$ are of crushed limestone and $\mathrm{RS}$ is fine limestone river sand.

\subsection{Aggregate Test Program}

- Constituents of the coarse RA examined according to NP EN 933-11 [24], in which RA are grouped in the following categories:

Rc - concrete, concrete products, masonry concrete blocks;

$\mathrm{Ru}$ - unbounded aggregates, natural stone, treated aggregates with hydraulic binder;

$\mathrm{Rb}$ - ceramic elements (e.g. bricks, roof tiles, etc), not floating cellular concrete and masonry blocks;

Ra- bituminous materials;

$\mathrm{Rg}$ - glass;

$X$ - cohesive materials (soil, clay, etc.), metals, wood, plastic, rubber, stucco;

$\mathrm{FL}$ - floating materials.

- Particle size distribution according to NP EN 933-1 [25].

- Size class according to NP EN 12620 [26].

- Mytilene blue according to NP EN 933-9 [27].

- $\quad$ Sand equivalent according to NP EN 933-8 [28].

- Shape index according to NP EN 933-4 [29].

- Wet and dry specific densities according to da NP EN 1097-6 [30] .

- Water absorption according to NP EN 1097-6 a [30] and water absorption along the time. It was used the pycnometer method and the readings were realized at: $10 \mathrm{~min} ; 20 \mathrm{~min} ; 40$ min; 60 min; 90 min; 2h; 3h; 5h; 7h; 24h.

- Los-Angeles Coefficient according to NP EN 1097-2 [31]. 
- Drying shrinkage according to EN NP 1367-4 [32]. It were designed and executed one reference mix with the four NA and 3 mixes with RA. In this mixes the coarse NA was substituted by each type of RA and the fine NA was kept. It was necessary to add extra water, equivalent to the aggregate absorption capacity, to enable the compaction of the specimens.

- The mass stability was obtained by measuring the mass variation in one drying and wetting cycle described in the EN NP 1367-4 [32].

\subsection{Aggregate Test Results and Discussion}

\subsubsection{Constituent Tests}

Table 1: Constituents of aggregates

\begin{tabular}{|l|l|l|l|l|l|l|l|}
\hline Aggregate/Constituent & $\mathbf{R c}(\%)$ & $\mathbf{R u}(\%)$ & $\mathbf{R b}(\%)$ & $\mathbf{R a}(\%)$ & $\mathbf{R g}(\%)$ & $\mathbf{X}(\%)$ & $\mathbf{F L ~ ( c m} \mathbf{~}^{\mathbf{k g}} \mathbf{)}$ \\
\hline RA1 & 74.50 & 21.30 & 3.57 & 0.14 & 0.10 & 0.40 & 0.55 \\
\hline RA2 & 37.26 & 26.20 & 34.06 & 0.08 & 0.03 & 2.38 & 0.62 \\
\hline RA3 & 52.40 & 10.20 & 37.20 & 0.07 & 0.05 & 0.09 & 7.13 \\
\hline
\end{tabular}

The major constituent of the RA is old concrete or mortar, followed by ceramic materials and natural stone. This is in agreement with the literature [33,34], where the natural stones are included in the concrete category. The crushing process might lead to a separation of natural stones from mortar. The fraction of other constituents is very low.

\subsubsection{Aggregate Test Results}

Table 2: Physical properties of aggregates

\begin{tabular}{|c|c|c|c|c|c|c|c|}
\hline Property/Aggregate & RS & CS & NA1 & NA2 & RA1 & RA2 & RA3 \\
\hline Size class & $0 / 2$ & $0 / 4$ & $4 / 12.5$ & $12.5 / 20$ & $4 / 20$ & $4 / 20$ & $6.3 / 25$ \\
\hline Fines (\%) & 1.5 & 1.8 & 0.8 & 0.3 & 2.9 & 5.6 & 1.4 \\
\hline Mytilene blue 0/2 (g/Kg) & 0.5 & 0.6 & \multirow{2}{*}{\multicolumn{2}{|c|}{$\begin{array}{l}----- \\
\end{array}$}} & 2.0 & 6.7 & 1.7 \\
\hline Sand equivalent 0/2 (\%) & 79.4 & 87.9 & & & 36.1 & 23.7 & 39.7 \\
\hline Shape index (\%) & \multicolumn{2}{|l|}{------ } & 15.0 & 10.0 & 9.7 & 24.2 & 29.2 \\
\hline Dry specific density & 2.626 & 2.662 & 2.648 & 2.283 & 2.286 & 2.162 & 2.096 \\
\hline Saturated specific density & 2.631 & 2.691 & 2.676 & 2.696 & 2.420 & 2.331 & 2.272 \\
\hline Water absorption & 0.2 & 1.1 & 1.1 & 0.5 & 5.9 & 7.8 & 8.4 \\
\hline LA (\%) & \multicolumn{2}{|l|}{------- } & 26.0 & 35.7 & 43.3 & 49.8 & 53.5 \\
\hline Drying shrinkage (\%) & \multicolumn{4}{|l|}{0.013} & 0.031 & 0.035 & 0.043 \\
\hline Mass stability (\%) & \multicolumn{4}{|l|}{4.6} & 7.6 & 8.5 & 8.9 \\
\hline
\end{tabular}

\subsubsection{Sieve Analysis}

According to figure 1, RA3 is coarser than RA1 and RA2 despite the same crushing process was followed. RA2 has significantly more fines. These differences may be attributed to the nature of its constituents, but all RA can give rise to a compact size distribution near to reference grades. RA shows generally higher content in fines than the NA. 


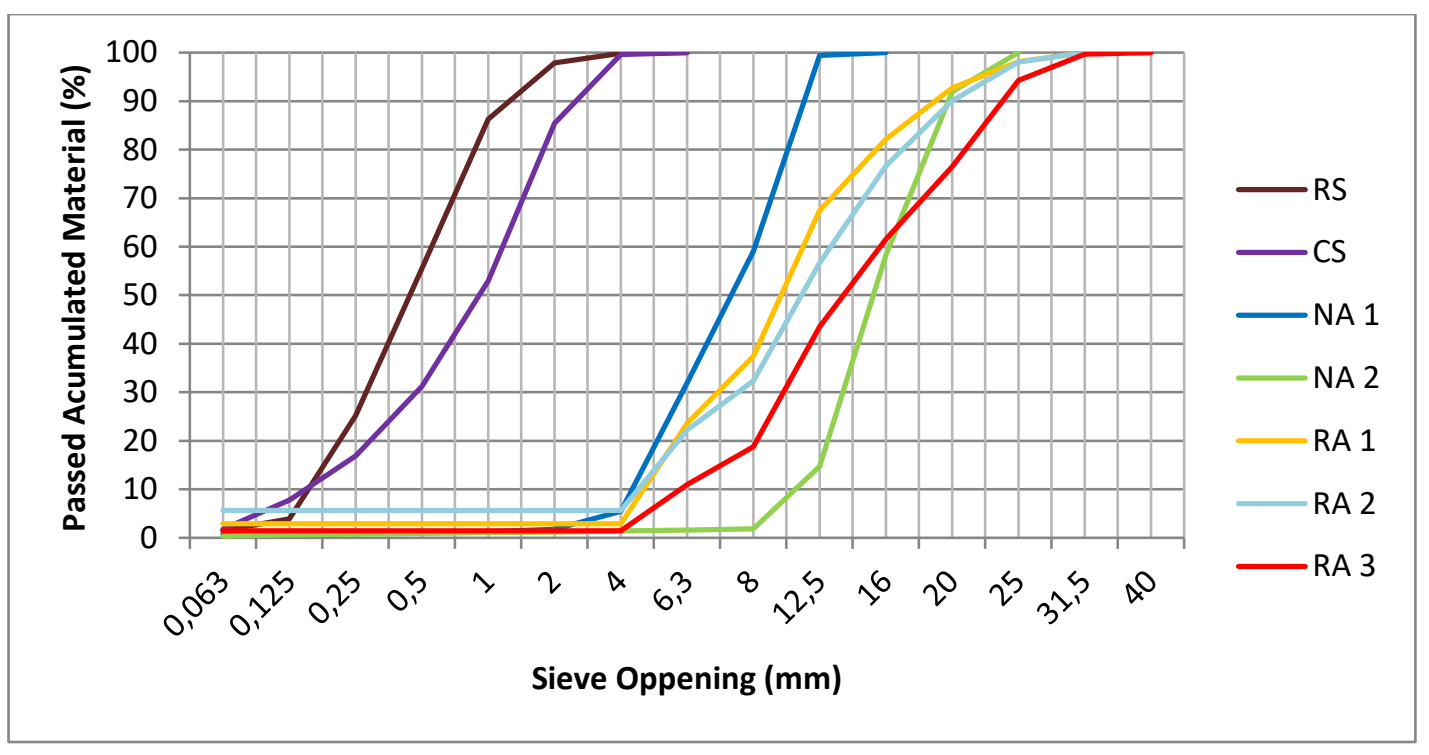

Figure 1: Aggregate sieve analysis

\subsubsection{Methylene Blue and Sand Equivalent}

The results show that the RA has higher fines contents and methylene blue values than the NA, particularly RA2, which might be associated to its higher clay content. It can also be concluded that the sand equivalent values follows the same trend than the methylene blue values.

\subsubsection{Shape Index}

The shape index of old concrete particles is lower than that of NA but it increases dramatically with the content of ceramic materials. Ceramic elements like bricks, roof, floor or wall tiles show a dimension much smaller than the other 2 dimensions, which causes a high shape indexes of ceramic RA. The results are in agreement with the reported by others [35, 36].

\subsubsection{Specific Density and Water Absorption}

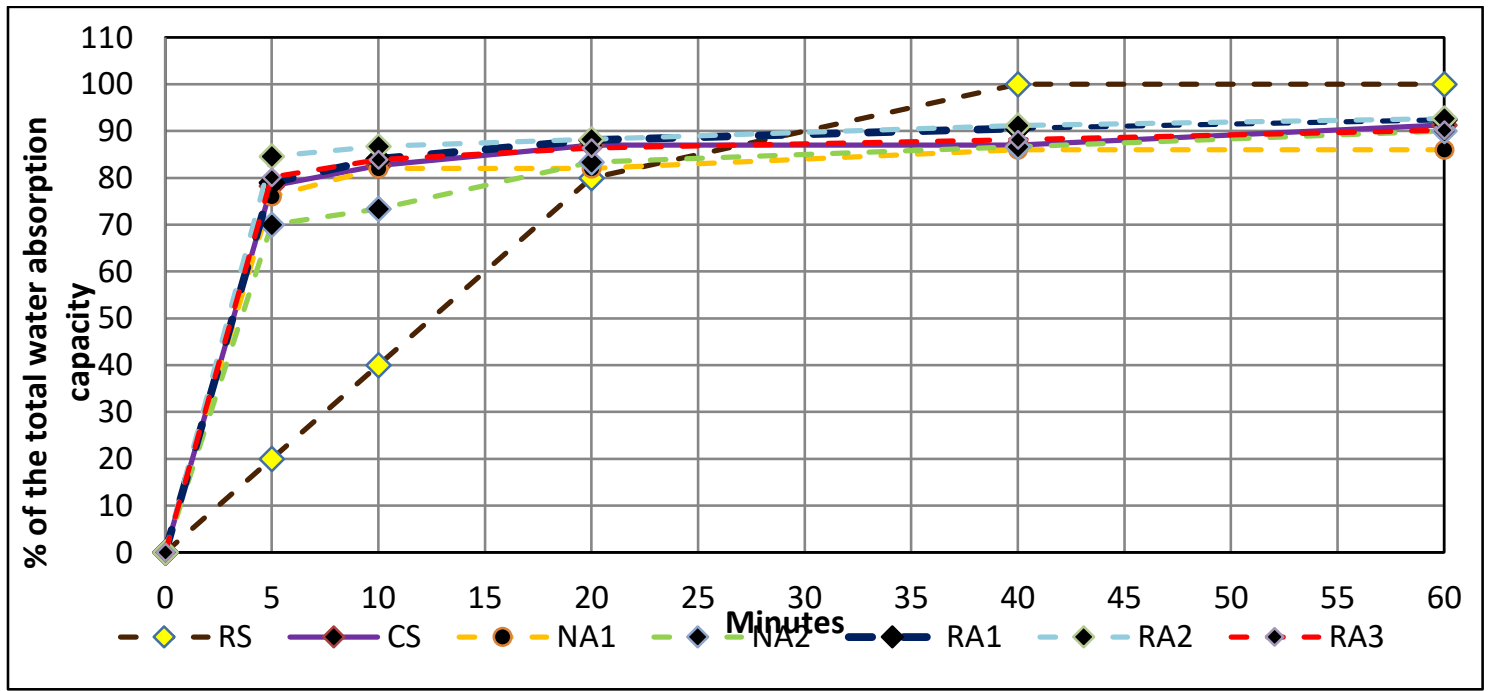

Figure 2: Aggregate water absorption in the 60 min in percentage of the total absorption capacity

With the exception of RS, water absorption behaviour is similar for all aggregates (Figure 2). This behaviour can be separated in 2 phases. In the 1st phase, a quick rate absorption occurs involving the superficial larger pores. In the 2nd, the absorption involves the deeper and smaller pores and takes place at a slower rate. For all aggregates the transition from the 1 st to the 2 nd phase occurs after 5 minutes, which matches a water absorption of about $80 \%$ of its maximum. The optimum 
amount of pre-saturation water and pre-saturation time should take place at the end of the 1st phase, i.e. after 5 minutes. RS only absorbs $0.2 \%$ water meaning that its behaviour is negligible. The absorption rate of the RA is somewhat faster than that of NA but the differences are negligible after 5 minutes. As expected, RA shows a higher water absorption capacity than the NA, and this increases with the content of ceramic material that can be matched to its densities.

The density of the 4 NA is in the expected range for limestone [36] and that of RA is much lower, decreasing with the content of ceramic particles. The values are also in the range obtained by others $[9,37]$.

\subsubsection{Los-Angeles Coefficient}

Los Angeles coefficients of RA are much lower than that of NA and decrease with the ceramic content, which can be related to the density trend. Similar results were found by Vegas et al [38] and Mas et al [34].

\subsubsection{Drying Shrinkage and Mass Stability}

The results presented in table 2 show that the reference shrinkage strain is very low, which may be related to the limestone properties [39].The incorporation of RA increases the shrinkage strain dramatically due to a bigger pore volume (diameter between 6-30 nm), specific surface area [39] and less stiffness [40], caused by the attached mortar. In the same way, drying shrinkage strain grows with the content of ceramic particles, which could be also related to the higher clay content [41]. Drying shrinkage is proportional to the mass stability which follows the water absorption trend.

\section{CONCRETE TEST PROGRAM AND MIXING METHOD}

\subsection{Mix Compositions}

The compositions were calculated by following the Faury's method. The cement and water content were further adjusted experimentally to reach a concrete class of C30/37 [42] and an initial slump of $130 \pm 20 \mathrm{~mm}$, corresponding to the workability class S3 [42]. Six compositions were prepared, one reference mix with NA (NAC) only, and 5 mixes with different types and percentages of RA (RA1C25\%; RA2C50\%; RA1C $100 \%$; RA2C100\% and RA3C100\%). The effective $\mathrm{W} / \mathrm{C}$ ratio is 0.6 in all mixes and the binder is a CEM I 42.5. Table 3 presents the mix compositions and table 4 the aggregate properties of the mixes.

Table 3: Mix compositions

\begin{tabular}{|c|c|c|c|c|c|c|}
\hline Materials/Mixes & NAC & $\begin{array}{c}\text { RA1C } \\
25 \%\end{array}$ & $\begin{array}{r}\text { RA1C } \\
50 \%\end{array}$ & $\begin{array}{l}\text { RA1C } \\
100 \%\end{array}$ & $\begin{array}{l}\text { RA2C } \\
100 \%\end{array}$ & $\begin{array}{l}\text { RA3C } \\
100 \%\end{array}$ \\
\hline $\mathrm{RS}\left(\mathrm{kg} / \mathrm{m}^{3}\right)$ & 289 & 281 & 274 & 261 & 250 & 246 \\
\hline $\mathrm{CS}\left(\mathrm{kg} / \mathrm{m}^{3}\right)$ & 343 & 334 & 325 & 310 & 297 & 292 \\
\hline $\mathrm{NA} 1\left(\mathrm{~kg} / \mathrm{m}^{3}\right)$ & 523 & 382 & 248 & \multirow{2}{*}{\multicolumn{3}{|c|}{0}} \\
\hline NA2 $\left(\mathrm{kg} / \mathrm{m}^{3}\right)$ & 649 & 474 & 308 & & & \\
\hline RA1-2-3 $\left(\mathrm{kg} / \mathrm{m}^{3}\right)$ & 0 & 285 & 556 & 1059 & 1018 & 998 \\
\hline CEM I 42,5 R $\left(\mathrm{kg} / \mathrm{m}^{3}\right)$ & \multicolumn{6}{|l|}{350} \\
\hline Water $\left(1 / \mathrm{m}^{3}\right)$ & \multicolumn{6}{|l|}{210} \\
\hline Extra Water $\left(\mathrm{I} / \mathrm{m}^{3}\right)$ & 9.52 & 20.94 & 31.8 & 51.98 & 69.83 & 69.91 \\
\hline
\end{tabular}


Table 4: Aggregate properties of the mixes

\begin{tabular}{|l|l|l|l|l|l|l|}
\hline \multicolumn{1}{|c|}{ Poperties/Mixes } & NAC & $\begin{array}{c}\text { RA1C } \\
\mathbf{2 5 \%}\end{array}$ & $\begin{array}{c}\text { RA1C } \\
\mathbf{5 0 \%}\end{array}$ & $\begin{array}{c}\text { RA1C } \\
\mathbf{1 0 0} \%\end{array}$ & $\begin{array}{c}\text { RA2C } \\
\mathbf{1 0 0} \%\end{array}$ & $\begin{array}{l}\text { RA3C } \\
\mathbf{1 0 0} \%\end{array}$ \\
\hline Water Absorption (\%) & 0.74 & 2.03 & 3.31 & 5.88 & 7.83 & 8.41 \\
\hline Dry Density & 2.67 & 2.58 & 2.48 & 2.29 & 2.16 & 2.10 \\
\hline Shape Index (\%) & 12.23 & 11.69 & 11.12 & 9.71 & 24.24 & 29.24 \\
\hline LA (\%) & 31.54 & 34.46 & 37.27 & 43.28 & 49.84 & 53.46 \\
\hline
\end{tabular}

\subsection{Mixing Method}

A two-staged mixing approach (Figure 3) was designed to overcome the high water absorption of the RA and mitigate any negative effects of the concrete properties on its fresh and hardened state. After the first mixing stage all the extra water should be absorbed and the cement can be introduced without influencing the effective W/C ratio and the ITZ water flow, at any stage of microstructure evolution of concrete. The second mixing stage was of $2 \mathrm{~min}$, the time required to obtain a homogeneous consistency. A 5 minutes time was taken for the first mixing stage (Figure 2). A percentage of extra water to compensate the aggregate water absorption was also deduced from Figure 2. After mixing, a slump test was prepared during 3 hours to verify if the chosen pre-saturating time and amount of extra water reaches the optimum humidity state of the aggregates.

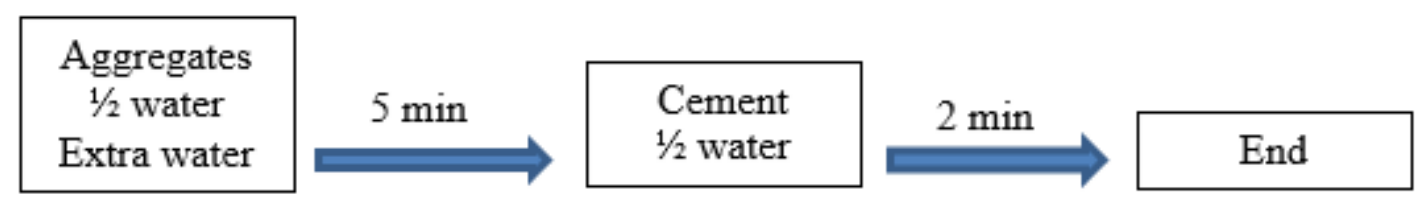

Figure 3: Two-staged mixing method

\subsection{Concrete Property Tests}

In the fresh state a long term workability test was performed to evaluate the water flow in the ITZ and the concrete's performance. In the hardened state tests were performed to evaluate the mechanical, physical and durability properties of the RAC.

- Workability was evaluated by the slump test according to NP EN 12350-2 [43]. The first reading was executed after finish the mix and the following readings were taken every $30 \mathrm{~min}$ for 3 hours. The materials were kept at $20.5 \pm 2 \stackrel{\circ}{\circ}$ and the mixing room was maintained at $23 \pm 1 \stackrel{\circ}{ } \mathrm{C}$. The relative humidity was not controlled. Between measurements the fresh concrete stayed in the stopped mixer, which was covered, but the moisture exchange with the surroundings was not completely avoided. Before each test the mixer was turned on for about $20 \mathrm{~s}$ to break the concrete bonds.

- Compressive strength was tested in cubes with a $15 \mathrm{~cm}$ edge according to NP EN 123901 [44]. The specimens were compacted and cured according to NP EN 12390-2 [45]. The compaction was executed through tamping indicated for this workability class [46]. Three specimens were tested after a curing time of 28 days and another three at the age of 91 days, according to NP EN 12390-3 [47].

- Water absorption by immersion and specific density was tested in specimens equal to that of compressive strength, subjected to the same curing conditions. The tests were 
performed after a curing time of 91 days according to E 394 [48] and NP EN 12390-7 [49], respectively.

- Shrinkage and mass loss were measured in prisms of size $5 \times 5 \times 20 \mathrm{~cm}$, according to $\mathrm{E} 398$ [50]. The maximum aggregate size was too big for the molds. Sieving of fresh concrete throw a mesh of $12.5 \mathrm{~mm}$ was performed. The readings were performed at the age of: 1 , $7,15,29,61$ and 91 days.

\subsection{Workability}

\section{RESULTS AND DISCUSSION}

Figure 4 clearly shows that the ITZ water flow from the RA is nearly suppressed and that the swelling after $30 \mathrm{~min}$ is almost negligible. The observed small swelling is probably due to the superficial absorption by the natural sand. The slump decrease is nearly linear and the workability changes on time follow the same pattern indicating that there is no water absorption from the aggregates. NA mixes had significant swellings in the first $30 \mathrm{~min}$. This result was unexpected, as their absorption rates were found to be lower than those of RA and at the stage of 5 min they reached only $70 \%$ of their absorption capacity. The test results shows that the staged mixing approach, with the chosen parameters, can successfully eliminate the negative effects of recycled aggregate water absorption in concrete technology. The results indicate that this approach works for RA but should not be used for OC.

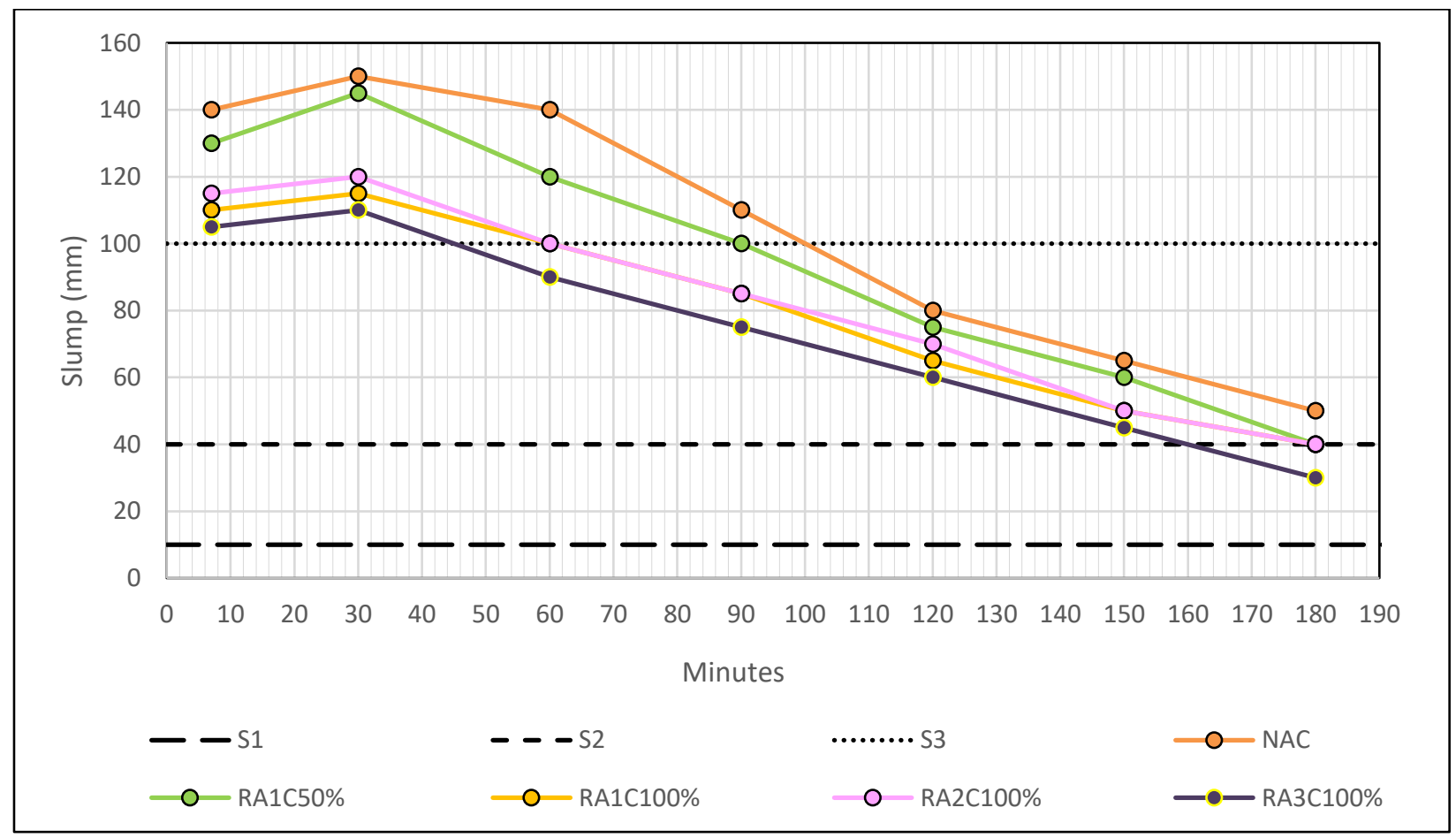

Figure 4: Slump test over time

Figure 4 shows that the NAC has the highest slump peak and the larges "S3" period. However, the slump reduction is negligible up to $50 \%$ substitution of RA1. The 3 mixes with $100 \%$ RA have a lower slump peak and "S3" period, but after 120 minutes the slump of all mixes became very similar. The initial mixing water was the same for all compositions; the somewhat lower slump of the $100 \%$ RAC is due to the higher surface roughness, shape index and the undesirable water flow explained previously. After 120 min the effect of the NA water loss relieves and the new mortar gets attached to the aggregates, lowering the initial slump differences between the mixes. On one hand the workability of RA1 concrete is reduced due to a greater friction between the rough particles. On the other RA2C $100 \%$ and RA3100\% had a shape index more than 2 times higher when compared to other mixes, affecting the rheology of the fresh concrete. 


\subsection{Compressive Strength}

Table 5: Compressive Strength

\begin{tabular}{|c|c|c|c|c|c|c|}
\hline Strength/Mixes & NAC & $\begin{array}{c}\text { RA1C } \\
25 \%\end{array}$ & $\begin{array}{c}\text { RA1C } \\
50 \%\end{array}$ & $\begin{array}{l}\text { RA1C } \\
100 \%\end{array}$ & $\begin{array}{l}\text { RA2C } \\
100 \%\end{array}$ & $\begin{array}{l}\text { RA3C } \\
100 \%\end{array}$ \\
\hline 28 Days & 39,5 & 39,5 & 39,0 & 37,5 & 28,3 & 29,7 \\
\hline 91 Days & 41,5 & 41,2 & 40,2 & 40,5 & 32,7 & 34,3 \\
\hline Strength Class & \multicolumn{4}{|c|}{ C30/37 } & \multicolumn{2}{|l|}{$\mathrm{C} 20 / 25$} \\
\hline Decrease at 28 days (\%) & \multirow[t]{2}{*}{$/ / / /$} & 0,0 & 1,3 & 5,1 & 28,4 & 24,9 \\
\hline Decrease at 91 days (\%) & & 0,8 & 3,2 & 2,4 & 21,3 & 17,3 \\
\hline
\end{tabular}

At the age of 28 days, up to a RA 1 content of $50 \%$, the strength reduction relatively to reference mix is negligible. Even RA1C100\% decreased in an acceptable range and keeps the same strength class. RA2C $100 \%$ and $\mathrm{RA} 3 \mathrm{C} 100 \%$ had a significant strength loss relatively to the reference mix, affecting the strengths class. At the age of 91 days the strength difference between the $100 \%$ RAC mixes NAC lowered substantially. This behavior was not observed for the compositions prepared with both types of aggregate, RA and NA. The improvement of the RAC strength relative to that of NAC, from 28 to 91 days, is about $7 \%$ in the mixes with ceramic material but there is no clear trend in the RA1C. This observation cannot be explained by the late reactions of old not hydrated cement [7]. This result can be explained considering that a lower stiffness of the RA reduces the restraint degree and thus the microcracking perpendicular to the aggregates. Moreover the internal curing from the saturated RA attenuates the overall shrinkage strain, giving rise to an additional minimization of the microcracking.

The absence of ITZ water flow enables formation a compact ITZ microstructure [4] and ensures that the extra water does not affect the effective W/C ratio. Other aggregate properties account for the differences between RAC and NAC. For example, as the LA coefficient raises the strength decays (Tables 2 and 5). Ductile aggregates cause a load distribution to the cement paste and ITZ during the strength test. On the other hand, the poorer strength of the RA, particularly of ceramic particles, can lead to failure through the aggregates. The significant amount of low quality fines RA reduces the contact zones in the aggregate structure, compromising the concrete strength. Comparing RA2C with RA3C, the worse fines content and quality of RA2C have a stronger effect than the LA coefficient trend. Other factors that may contribute to the differences between RA1C and RA2C/RA3C are the shape index and the surface roughness. Ceramic particles show one or two flat surfaces, which influence negatively the bond strength. Elongated or flattened aggregate shapes can lead to less effective compaction and need more mortar to fill the aggregate void structure.

For practical purposes RA1 is appropriated for concrete preparation up to a C30/37 strength class. RA2 and RA3 should be used only for strength classes up to C20/25.

\subsection{Shrinkage and Mass Loss}

Figure 5 shows that the mass loss increases with the RA content and its percentage of ceramic material. The observed pattern is in agreement with the aggregate water absorption capacity and mass stability presented on Table 2 . After 28 days the water loss trends of the different mixes evolve in a parallel pattern indicating all the water was lost from the aggregates before this age. The mass loss observed after 28 days is probably due to gel water flow of the hydrating cement paste, which is present in the same content for all mixes. 
M. Eckert, M. Oliveira, Mitigation of the Negative Effects of Recycled Aggregate Water Absorption in Concrete Technology

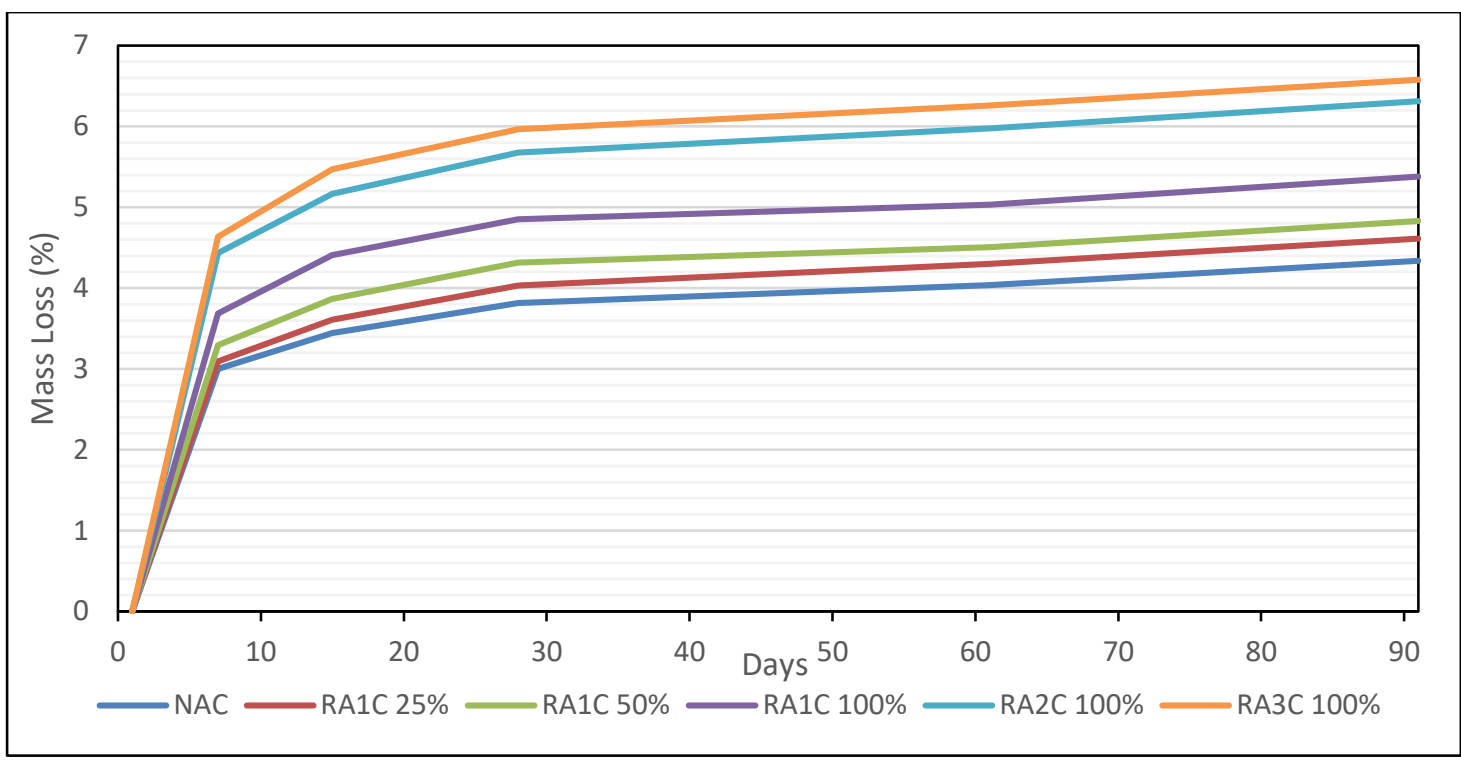

Figure 5: Concrete Mass Loss

Figure 6 shows that the $100 \%$ RAC mixes shrinks more than concrete containing NA, due to a larger aggregate shrinkage (3.2.6). From comparison of the 3 mixes containing NA or both types of aggregate it can be noted that for the first 7 days the internal curing, provided by the saturated RA, is more influent than the lower shrinkage of the NA. After this period the "water deposits" drain and consequently the internal curing loses efficiency. The lowered shrinkage strain and degree of internal restraint in the first 7 days enables the development of tensile strengths and may avoid cracking

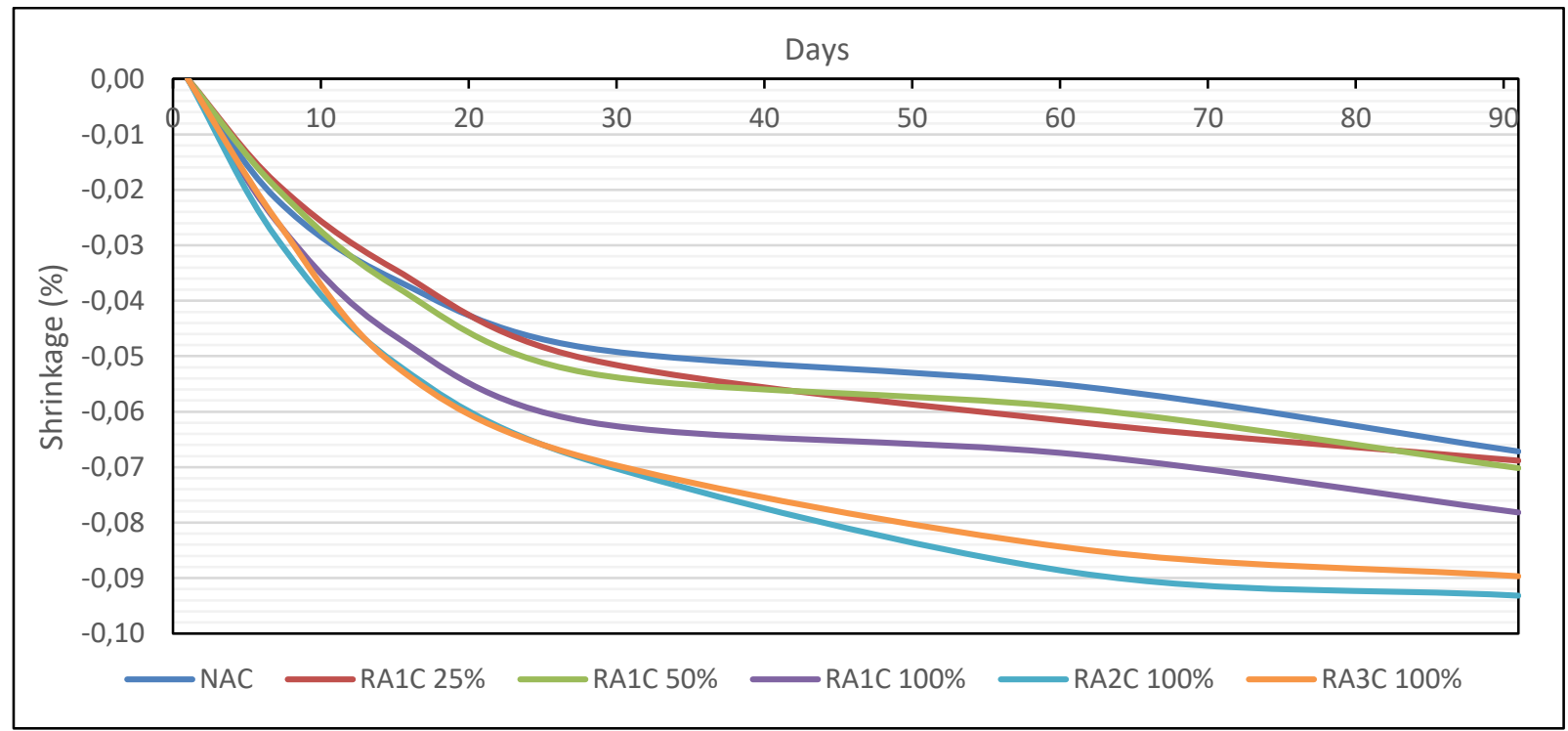

Figure 6: Concrete Shrinkage

Comparing the $100 \%$ RAC mixes it can be seen that the significant content of low quality fines of RA2C $100 \%$ is more influent than the lower degree of internal restraint of RA3C $100 \%$. The high fines content reduces the pore radius and increases the capillary pressure. Moreover, the absorbed water layers, evaluated by the methylene blue test, increase the surface tension, swelling pressure and the movement of interlayer water.

From the shrinkage test it can be concluded that the used mixing process transforms the negative effect of RA water absorption in a technique to reduce the sensibility of early age cracking. It is also clear that the internal curing cannot compensate the lower stiffness of the $100 \%$ RAC mixes. 


\subsection{Water absorption by immersion and density}

Table 6 shows that the water absorption increase and density decrease as function of the RA content. The measured differences of the water absorption capacities of NAC and RAC are similar to the calculated ones (Table 4). This result indicates that the cement slurry wasn't able to reduce the aggregate absorption capacity by sealing the pores. The same cannot be observed between the measured and calculated densities. The calculated density decrease from the NAC to the RAC (Table 4) is in average $45 \%$ higher than the measured ones (Table 6 ) meaning that the mortar seals some superficial pores of the aggregates which is more evident in lower density aggregates.

Table 6: Physical properties of the concrete mixes

\begin{tabular}{|l|l|l|l|l|l|l|}
\hline \multicolumn{1}{|c|}{ Properties/Mixes } & NAC & $\begin{array}{c}\text { RA1C } \\
\mathbf{2 5} \%\end{array}$ & $\begin{array}{c}\text { RA1C } \\
\mathbf{5 0} \%\end{array}$ & $\begin{array}{c}\text { RA1C } \\
\mathbf{1 0 0} \%\end{array}$ & $\begin{array}{l}\text { RA2C } \\
\mathbf{1 0 0} \%\end{array}$ & $\begin{array}{l}\text { RA3C } \\
\mathbf{1 0 0} \%\end{array}$ \\
\hline Water absorption (\%) & 15.5 & 17.0 & 18.9 & 21.1 & 22.8 & $\mathbf{2 2 . 5}$ \\
\hline Saturated Specific density & 2.39 & 2.35 & 2.31 & 2.25 & 2.20 & 2.15 \\
\hline Dry specific density & 2.23 & 2.28 & 2.12 & 2.04 & 1.97 & 1.93 \\
\hline Weight 28 days $(\mathrm{g})$ & 8145 & 8070 & 7931 & 7775 & 7529 & 7404 \\
\hline Weight 91 days $(\mathrm{g})$ & 8198 & 8060 & 7963 & 7785 & 7538 & 7443 \\
\hline
\end{tabular}

The results clearly show that the staged mixing approach is able to reduce the water flow from the fresh concrete, but the long term water flow does not change. Durability of concrete is generally connected to its water absorption capacity because water transports ions into the concrete which potentiates its degradation and corrosion of the reinforcement. Therefore RAC should be protected from moisture in aggressive environments. The water flow capacity in the hardened state also allows internal curing provided by the saturated aggregates, reducing shrinkage cracking. It should also be mentioned that the low aggregate density has positive effects on concrete structures. Low density concrete reduces the structural deadweights allowing the use of smaller structural sections which can compensate the above mentioned strength decrease. Moreover the low densities reduce the thermal conductivity of concrete and consequently the thermal bridges, improving the insolating capacity of buildings.

\section{CONCLUSIONS}

It was demonstrated that the staged mixing approach can be followed to reduce the ITZ water flow of RAC to a negligible amount, in its fresh state. The extra water does not affect the effective W/C and a compact ITZ structure can be develop [4]. A pre-saturation time of 5 minutes and the corresponding extra water incorporated in a two staged mixing approach, mitigates the negative effect of recycled aggregate water absorption in concrete technology. However the procedures should not be followed for natural aggregates

Long term water flow from saturated aggregates to the surrounding cement paste matrix associated to a lower degree of restraint, reduces microcracking improving the strength of RAC. Despite the control of water flow the ITZ properties of RAC show lower quality properties than that of NAC, which can be attributed to the aggregate properties such as the LA coefficient, shape index, fines content and quality and specific density. All mentioned aggregate properties reduce with the content of ceramic material.

The maximum slump and "S3" period of the RAC is somewhat lower than that of NAC due to the aggregate surface roughness and higher shape index. Pre-saturation of the RA reduces the fast slump decrease and the high amount of mixing water, needed to compensate this decrease, as observed by Poon et al [6] 
The shrinkage test showed that the used mixing process transforms the negative effects associated to RA water absorption in a technique to reduce the sensibility of early age cracking. However the internal curing cannot compensate the lower stiffness of the $100 \%$ RAC mixes.

The deadweight of RAC is lower than that of NAC allowing for a reduction in the section of the structural elements. This effect may compensate the somewhat lower strength of RAC.

$100 \%$ RAC concrete made of RA with low ceramic material content can substitute NAC up to a strength class of $\mathrm{C} 30 / 37$ and a workability class of S3. 100\% RAC with high ceramic material content should not be used for strength classes higher than $\mathrm{C} 20 / 25$.

Considering that the costs of RA are $60-80 \%$ lower than NA, RAC brings economic and environmental benefits for consumers. The high water absorption capacity of RA, if used in appropriate manner, should be viewed as a benefit and not as a problem because it provides internal curing of the concrete.

Further investigation must be done to improve the crushing process of RAC with the goal to reduce the high shape index of ceramic particles. Fine RA should be tested to see if the ITZ water flow can be completely mitigated. It should be investigated if the mixing process reduces early age cracking of concrete. New structural conceptions must be studied to overcome the lower stiffness of RAC.

\section{REFERENCES}

[1] M. Botelho, Resíduos de Construção e Demolição, Verlag Dashoefer, 2010.

[2] B. Damineli , . F. Kemeid, . P. Aguiar and V. John, Measuring the eco-efficiency of cement use. Cem. Concr. Compos. 32, 2010, p. 555-562.

[3] E 471-2009, Guia para a utilização de agregados reciclados grossos em betões de ligante hidráuliocos, LNEC, 2009.

[4] V. W. Tam, . X. Gao and C. Tam, Microstructural analysis of recycled aggregate concrete produced from two-stage mixing approach, Cement and Concrete Research 35, 2005, p. 1195-1203.

[5] K. Crentsil Sagoe , T. Brown and . A. Taylor, Performance of concrete made with commercially produced coarse recycled concrete aggregate. Cem Concr Res, 2001, p. 31:707-12.

[6] C. Poon, . Z. ShuiL, L. Lam, H. Fok and S. Kou, Influence of moisture states of natural and recycled aggregates on the slump and compressive strength of concrete, Cement and Concrete Research 34, 2004, p. 31-36.

[7] L. Evangelista and J. de Brito, Mechanical behaviour of concrete made with fine recycled concrete aggregates, Cement \& Concrete Composites 29, 2007, p. 397-401.

[8] C. Poon, . Z. Shui and . L. Lam, "Effect of microstructure of ITZ on compressive strength of concrete prepared with recycled aggregates," Construction and Building Materials, vol. 18, p. 461-468, 2004.

[9] C. S. Poon and. D. Chan, Feasible use of recycled concrete aggregates and crushed clay brick as unbound road sub-base Construction and Building Materials 20, 2006, p. 578-585.

[10] M. Exteberria, . E. Va'squez and A. R. Mar1', Influence of amount of recycled coarse aggregates and production process on properties of recycled aggregate concrete. Cement and Concrete Research, 37, 2007, p. 735-742.

[11] B. Topçu and S. Sengel , Properties of concretes produced with waste concrete aggregate. Cem Concr Res., 2004, p. 34(8):1307-12. 
[12] A. Rao, Experimental Investigation on Use of Recycled Aggregates in Mortar and Concrete. Thesis submitted to the Department of Civil Engineering, Indian Institute of Technology Kanpur, 2005.

[13] M. Oliveira , d. Barra and E. Vazquez, The influence of retained moisture in aggregates from recycling on the properties of new hardened concrete, Waste Manage, 1996, p. 16:113$7 .$.

[14] A. Ajdukiewicz and A. Kliszczewicz, Influence of recycled aggregates on mechanical properties of HS/HPC,Cement \& Concrete Composites 24 (, 2002, p. 269-279.

[15] J. Khatib, Properties of concrete incorporating fine recycled aggregate, Cement and Concrete Research 35, 2005, p. 763-769.

[16] T. H.-K. Kang, W. Kim, . Y.-K. Kwak and S.-G. Hong, The choice of recycled concrete aggregates for flexural members. In Proceedings of 18th international association for bridge and structural engineering congress on innovative infrastructures, Seoul, Korea, 2012.

[17] A. Katz , Properties of concrete made with recycled aggregate from partially hydrated old concrete. Cem Concr.Res, 2003, p. 33:703-11..

[18] . L. F. R. Miranda and . S. M. S. Selmo, CDW Recycled Aggregate Renderings: Part IAnalysis of the Effect of Materials Finer than $75 \mu \mathrm{m}$ on Mortar Properties," Construction and Building Materials, Vol. 209, 2006, pp. 615-629.

[19] F. Debieb and S. Kenai, The use of coarse and fine crushed bricks as aggregate in concrete, Construction and Building Materials 22, 2008, p. 886-893.

[20] T. Kibriya and P. Speare , The use of crushed brick coarse aggregate in concrete. In: Proceedings of the international conference, Dundee;, 1996., p. 495-503.

[21]. S. M. Levy and P. Helene, Durability of recycled aggregates concrete: a safe way to sustainable development. Cem Conc Res, 2004, p. 1975-1980.

[22] T.-Y. Tu, . Y.-Y. Chen and C.-L. Hwang, "Properties of HPC with recycled aggregates," Cement and Concrete Research, vol. 36 , p. 943 - 950, 2006.

[23] K. Sagoe-Crentsil, T. Brown and A. Taylor, Performance of concrete made with commercialy produced coarse recycled concrete aggregate, Cement and Concrete Research 31, 2001, pp. 707-712.

[24] N. E. 9.-1. 2011, Ensaios das propriedades geométricas dos agregados. Parte 11: Ensaio para classificação dos constituintes de agregados grossos reciclados, 20011.

[25] NP EN 933-1, Ensaios das propriedades geométricas dos agregados. Parte 1: Análise granulométrica, Método de peneiração, IPQ, 2000.

[26] NP EN 12620, Agregados para betão, IPQ, 2004.

[27] NP EN 933-9, Ensaios das propiedades geométricas dos agregados, Parte 9: Determinação do teor de finos, Ensaio do azul de metileno, IPQ, 2002.

[28] NP EN 933-8, Ensaios das propriedades geométricas dos agregados, Parte 8: Determinação do teor de finos, Equivalente de areia, IPQ, 2002.

[29] NP EN 933-4, Ensaios das propriedades geométricas dos agregados, Parte 4: Determinação da forma das partículas-Índice de Forma.

[30] NP EN 1097-6, Ensaios das propriedades mecânicas e físicas dos agregados. Parte 6: Determinação da massa volúmica e da absorção de água.

[31] NP EN 1097-2, Ensaios das propriedades mecânicas e físicas dos agregados, Parte 2: Método para a determinação da resistência à fragmentação, 2002.

[32] 1.-4. N. EN, nsaios das propriedades térmicas e de meteorização dos agregados. Parte 4: Determinação da retração por secagem, IPQ, 2002.

[33] J. Yang, Q. Du and Y. Bao, "Concrete with recycled concrete aggregate and crushed clay bricks," Construction and Building Materials , vol. 25, pp. 1935-1945, 2011. 
[34] B. Mas, A. Cladera, T. del Olmo and F. Pitarch, Influence of the amount of mixed recycled aggregates on the properties of concrete for non-structural use, Construction and Building Materials 27, 2012, pp. 612-622.

[35] D. Matias, . J. de Brito, A. Rosa and . D. Pedro, Mechanical properties of concrete produced with recycled coarse aggregates - Influence of the use of superplasticizers, Construction and Building Materials 44, 2013, pp. 101-109.

[36] P. B. Cachim, Mechanical properties of brick aggregate concrete, Construction and Building Materials 23, 2009, p. 1292-1297.

[37] J. Yang, Q. Du and Y. Bao, Concrete with recycled concrete aggregate and crushed clay bricks, Construction and Building Materials 25, 2011, pp. 1935-1945.

[38] I. Vegas , . J. Ibañez, A. Lisbona and . A. Sáez de Cortazar, Pre-normative research on the use of mixed recycled aggregates in unbound road sections.Constr Build Mater, 2011.

[39] W. Zhang, . M. Zakaria and . Y. Hama, "Influence of aggregate materials characteristics on the drying shrinkage properties of mortar and concrete," Construction and Building Materials, vol. 49, p. 500-510, 2013.

[40] M. Eckert, Avaliação da Influência da Retração Inicial no Controlo da Fissuração dos Betões, Escola de Ciências e Tecnologia, Universidade de Évora, Évora: Universidade de Évora, 2014.

[41] R. Smith and L. Collis, Aggregates, sand, gravel and crushed rock aggregates for construction purposes, 3 (Special Edition) ed., vol. 17, Geological Society.

[42] NP EN 206-1, Betão. Parte 1: Especificação, produção e conformidade.

[43] NP EN 12350-2, Ensaios do betão fresco, Parte 2: Ensaios de abaixamento, Portugal: IPQ, 2002.

[44] NP EN 12390-1, Ensaios do betão endurecido, Parte 1: Forma, dimensões e outros requisitos para o ensaio de provetes e para os molde, Portugal: IPQ, 2003.

[45] NP EN 12390-2 2003, Ensaios de betão endurecido. Parte2: Execução e cura dos provetes para ensaios de resistência mecânica, IPQ, 2003.

[46] A. De Sousa Coutinho, Fabrico e propriedades do betão.

[47] NP EN 12390-3, Ensaios do betão endurecido, Parte 3: Resistência à compressão dos provetes de ensaio, Portugal: IPQ, 2003.

[48] E 394, Betões. Determinação da absorção de água por imersão, LNEC, 1993.

[49] NP EN 12390-7, Ensaios de betão endurecido. Parte 7: Massa volúmica de betão, IPQ, 2003.

[50] E 398, Hardened concrete. Determination of shrinkage and swelling, LNEC, 1993.

[51] A. Rao, , Experimental Investigation on Use of Recycled Aggregates in Mortar and Concrete. Thesis submitted to the Department of Civil Engineering, Indian Institute of Technology Kanpur, 2005.

[52] B. Mas, A. Cladera, T. del Olmo and F. Pitarch, "Influence of the amount of mixed recycled aggregates on the properties of concrete for non-structural use," Construction and Building Materials , vol. 27, p. 612-622, 2012.

[53] M. Eckert, D. Mendes, J. Gonçalves and M. Oliveira, "Quality Assessment and Classification of Recycled Aggregates from C\&DW According to the European Standards," 2015. 